\title{
HUMAN FACTOR MANAGEMENT IN FIRE PROTECTION AND IN EVACUATION FROM PUBLIC UTILITY OBJECTS
}

doi: $\quad 10.2478 /$ czoto-2019-0012

Date of submission of the article to the Editor: $30 / 11 / 2018$

Date of acceptance of the article by the Editor: 05/02/2019

Mariusz Sroka ${ }^{1}$ - orcid id: 0000-0002-4314-1482

${ }^{1}$ Czestochowa University of Technology, Poland, mariusz.sroka@wz.pcz.pl

Abstract: The study presents general assumptions of policies related to fire protection and evacuation of public buildings. Have been defined groups of human factors that have a significant impact on the efficiency of preventive actions taken and in the event of a threat. Next, the research methodology and results of questionnaire surveys carried out in randomly selected student groups are presented. A number of management actions aimed at increasing the safety of people staying on public facilities have been identified. The article ends with conclusions from the conducted research.

Keywords: management, human factor, fire protection, evacuation, security

\section{INTRODUCTION}

The human factor is the most unpredictable element in any security system. Generally, it is defined as: "the factor caused by specific individuals and groups of people filling organizational structures and implementing in their organizations the duties and tasks resulting from their roles as well as their own private goals and aspirations." In special circumstances such as for example evacuation in the situation of immediate threat to life and health, "private goals" understood as instinctive behavior outweigh the duties and tasks resulting from the functions performed in the organization. The only way to overcome instinctive reflexes in reducing the unpredictability of the human factor is to learn the correct reactions so that they are almost automatic.

The dominant element in the cycle of tasks related to fire protection and evacuation of buildings is man, and thus the human factor is of fundamental importance for the correct and effective implementation of both preventive and immediate danger tasks. Therefore, it seems reasonable to distinguish groups of human factors as well as human factors that affect fire protection and evacuation of objects. This will allow the human factor to be controlled and managed to a greater extent and, as a result, to increase the safety of people staying in it. Bearing in mind that the role of the human factor in occupational safety and health management systems is dominant, it is necessary to adequately train people destined to perform managerial functions in the future - and such persons are students of management departments. Only learned 
and practiced procedures and rules of conduct can reduce the unpredictability and potential illogicality of the human factor.

Such actions require proper management and control in the scope of their implementation. This determines the commitment of all persons responsible for the tasks entrusted and all persons staying on the site. It can be noticed that the dominant element in this task cycle is man, and thus the human factor is very important in the correct and effective implementation of both preventive and immediate danger tasks. Therefore, it seems reasonable to distinguish groups of human factors as well as human factors that affect fire protection and evacuation of objects. This will allow to have the human factor under control and manage it and, as a result, to increase the safety of people staying in it. The intention of the author of this study was to make it utilitarian (Holubová, 2016), (Kopczewski et al., 2012), (Laurowski, 2010).

\section{HUMAN FACTOR - GENERAL CHARACTERISTICS AND SELECTED MODEL SHOTS}

The human factor can be defined as a factor caused by specific individuals and groups of people filling organizational structures and implementing in their organizations both duties and tasks resulting from their functions and roles, as well as their own private goals and aspirations.

The human factor is also the whole of issues that are applicable in designing, certification, training, technical service, which allow to find areas of interaction between man and other elements of the system. The human factor should take into account human capabilities and limitations that affect the safety and efficiency of its operation. The human factor is related to inadequate human action that results in a mistake (Dul et al., 2012).

Aspects of the human factor's operation find their reference in technical, environmental and organizational areas.

It is possible to isolate causal groups of events resulting from the human factor. Belong to them:

- Intentional conduct - intentional departure from operating procedures and / or regulations or deliberate disregard of standard operating procedures, restrictions, instructions or manuals;

- Lack of qualifications - incorrect operation resulting from lack of knowledge, skills, combined with lack of experience or training or inability to use devices and tools;

- Errors in communication - inadequate communication, misinterpretation or inability to communicate properly in a team, group of employees, as well as incorrect transmission of relevant information regarding the performance of specific activities;

- Procedural errors - unintentional withdrawal from compliance with procedures or regulations;

- Inability - employees, students, people are unable to perform certain activities due to physical or psychophysical indisposition (Patankar et al., 2017).

One of the developed models of the human factor is the so-called the SHELL model, which allows you to visualize the interactions between man and system components. The model name is the acronym of the first letters of the English words:

- Software - procedures, software, logistics (security policy, instructions);

- Hardware - machines (tools, equipment, work station); 
- Environment - surroundings and conditions (physical, organizational, political, economic) in which all elements of the system work;

- Liveware - man, his physicality: psyche, knowledge, attitude, culture, resistance to stress and performance standards determined by the employer (Patankar et al., 2017).

Analyzing the human factor in the field of fire protection and evacuation of objects, we should mention the most common threats and causes of human errors, which can be divided into two groups related to a harmful excess of factors and a harmful lack of factors. In the case of harmful shortcomings, one can mention: communication, knowledge, cooperation, resources, assertiveness and awareness. However, harmful redundant factors include: self-confidence, dispersion, fatigue, stress, pressure and excess norms (Tabor, 2015).

\section{RESEARCH METHODOLOGY}

Questionnaire surveys were carried out in two rounds from November 19 to December 1, 2018 and from January 21 to January 25, 2019. The respondents were first-year students at the Faculty of Management at the Częstochowa University of Technology. The selection of the research group was purposeful. The total population of the research group was 1076 people. The dean groups in which questionnaires were conducted were selected randomly. To ensure the representativeness of the research sample, its minimum size was determined to be 245 people. The condition for participation in the research was to agree to anonymously complete the questionnaire. 256 questionnaires were carried out, of which 246 questionnaires were classified after checking the correctness of the fulfillment, consistency and logic of the answers provided for further analysis. The questionnaire contained 10 closed questions with the possibility of indicating one answer.

The test results are summarized in tables or graphically. Tables and diagrams are based on dependence (1), illustrating the frequency of giving answers of type $y(y=a$, $b, \ldots)$ as part of the question $x(x=1,2,3, \ldots, 7,8)$.

$$
k_{x, y}=\frac{\sum e_{x, y}}{\sum E_{x}} \cdot 100[\%]
$$

wherein:

$\sum e_{x, y}$ - the number of responses such as $\mathrm{y}(\mathrm{y}=\mathrm{a}, \mathrm{b}, \ldots)$ provided under question $\mathrm{x}$,

$\sum E_{x}$ - total number of responses to question $\mathrm{x}$.

The aim of the conducted research was:

- Determining the percentage of respondents who received training in the field of fire protection;

- Determination (in its own assessment) of the degree of knowledge of the participants of the fire training;

- Determining the percentage of respondents who participated in the trial or actual evacuation of the facility;

- Getting to know the opinions of the respondents about the usefulness of trial alarms in a real threat situation;

- Determination of a group of factors having the most significant impact on activities in the field of fire protection and evacuation of facilities; 
- Determination of the factors having the most significant impact on activities in the field of fire protection and evacuation of facilities;

- Determination of the type of management actions aimed at minimizing the impact of the human factor on fire protection and evacuation of facilities.

The test results are presented graphically or compiled in tables and analyzed in the chapter below.

\section{PRESENTATION AND DISCUSSION OF RESEARCH RESULTS}

The first question asked about the participation of respondents in the training on fire protection. Three quarters of respondents indicate that they participated in such training, while a quarter responds that they did not participate. The reasons for not participating in the training may be, among others: absenteeism on a given day or the fact that people do not remember about such training. The results of the survey for this question are presented in Fig. 1.

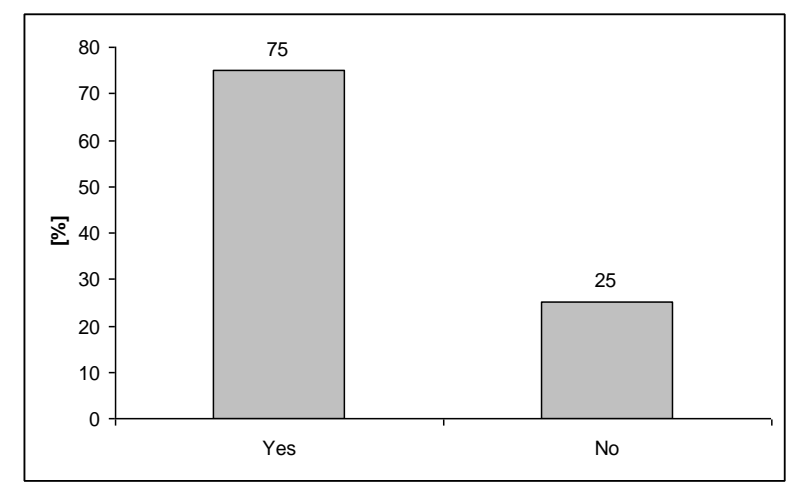

Fig. 1. Participation in training on fire protection

The next question was to get to know the opinions of the respondents, to what extent they remembered the transferred knowledge on training in the field of fire protection. High percentage of respondents, as many as $45 \%$ declare that they did not remember anything from such training, and $30 \%$ only half of the information provided. None of the respondents indicated the answer "everything". The reason is probably that the trainings are not conducted in an absorbing way and the knowledge transferred is not memorable and also that they are carried out sporadically at too long intervals. The results of the survey for this survey question are presented in Fig. 2.

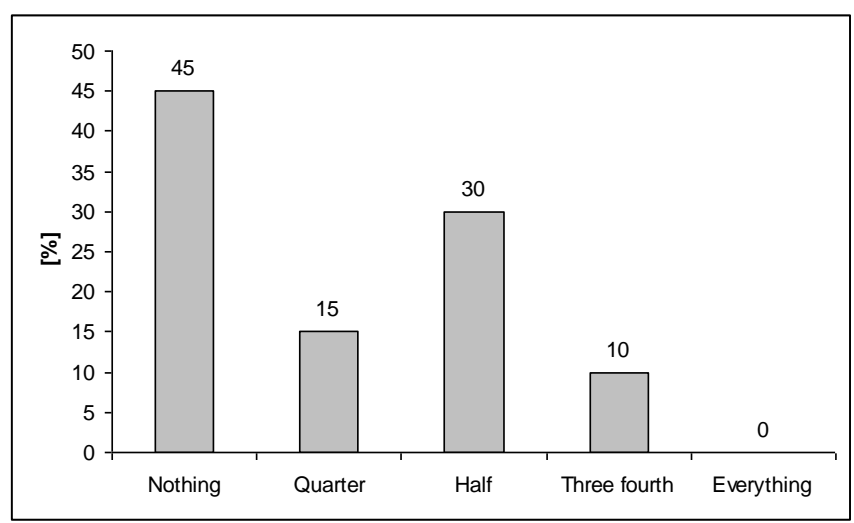

Fig. 2. Degree of memorized knowledge (in the opinion of the respondents) of fire training 
The next question was about taking part in the trial evacuation alarm or evacuating from the facility in a state of real danger. Only $20 \%$ of respondents indicate that they found themselves in this situation. As many as $80 \%$ of respondents never participated in a trial evacuation or real-life alarm. The main conclusion from this question is that most likely the persons responsible for conducting the evacuation of the objects neglect their duties. The results of the survey for this survey question are presented in Fig. 3.

The next question was to determine the suitability of the evacuation exercise from objects in a real threat situation. High, as many as $65 \%$ of respondents assess the evacuation test as very useful and $23 \%$ as moderately useful. Few, only $2 \%$ of the respondents rated the probable alarms in the situation of a real threat as not useful, and $10 \%$ as little useful. As we can see, the respondents rated the practical exercises very high, which is consistent with the known didactic principles confirming the superiority of practice on theory. The results of the survey for this question are presented in Fig. 4.

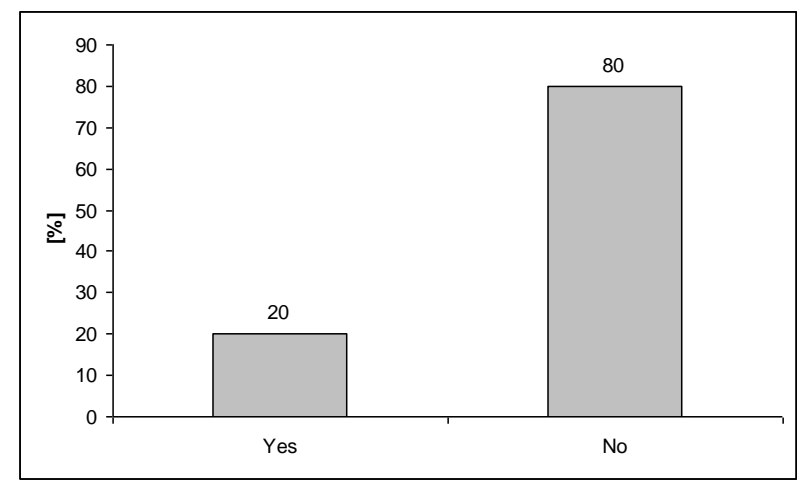

Fig. 3. Participation in a trial or real evacuation of the facility

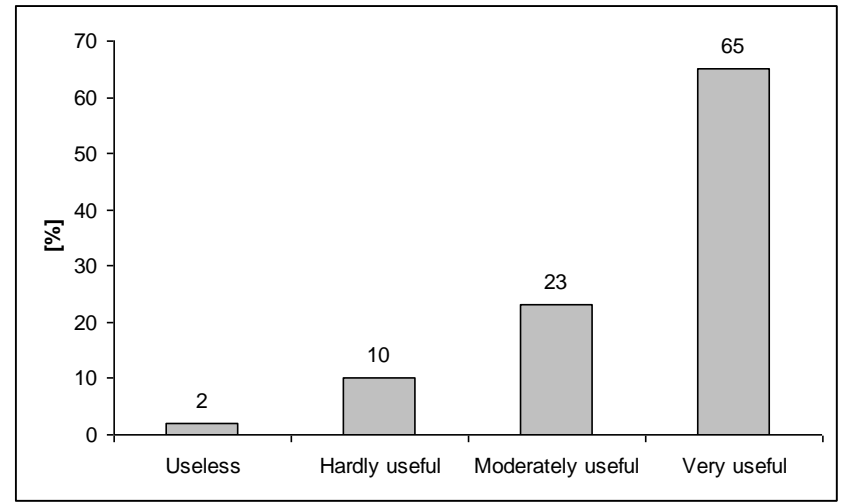

Fig. 4. Suitability of evacuation alarms in a real threat situation

In the next question, the respondents had to indicate groups of human factors which, in their opinion, have the greatest impact on activities undertaken in the field of fire protection. The group of factors indicated as the most important (33\%) is the lack of qualifications. The remaining ones with the highest indication are intentional proceedings $(30 \%)$ and procedural errors $(24 \%)$. The lowest number of indications was obtained by a group of human factors defined as psychophysical inability (2\%) and communication errors (11\%). The results of the survey for this survey question are presented in Table 1. 
In the next question, the respondents had to indicate groups of human factors which, in their opinion, have the greatest impact on the activities undertaken in the field of evacuation of objects. The respondents $(38 \%)$ indicated procedural errors. as the most important. Correspondingly, 25\% indicated errors in communication and $24 \%$ psychophysical inability. The smallest percentage of indications was obtained by a group of factors defined as intentional (6\%) and lack of qualifications (7\%). The results of the survey for this survey question are presented in Table 2.

The next question was to identify these human factors, the lack of which adversely affects the effectiveness of rescue and firefighting activities. The most frequently mentioned were: knowledge - 34\%, awareness - 32\% and communication - $26 \%$. The least frequently indicated factors are: resources and assertiveness of $2 \%$ and cooperation - 4\%. The results of the survey for this question are presented in Fig. 5.

Table 1

A group of human factors having the most significant impact on activities in the field of fire protection

Source: Own research

\begin{tabular}{|l|c|}
\hline \multicolumn{1}{|c|}{ Group of factors } & Indication [\%] \\
\hline Intentional proceedings & 30 \\
\hline Lack of qualifications & 33 \\
\hline Communication errors & 11 \\
\hline Procedural errors & 24 \\
\hline Psychophysical inability & 2 \\
\hline
\end{tabular}

Table 2

Group of human factors having the most significant impact on evacuation activities from the facility

\begin{tabular}{|l|c|}
\hline \multicolumn{1}{|c|}{ Group of factors } & Indication [\%] \\
\hline Intentional proceedings & 6 \\
\hline Lack of qualifications & 7 \\
\hline Communication errors & 25 \\
\hline Procedural errors & 38 \\
\hline Psychophysical inability & 24 \\
\hline
\end{tabular}

Source: Own research

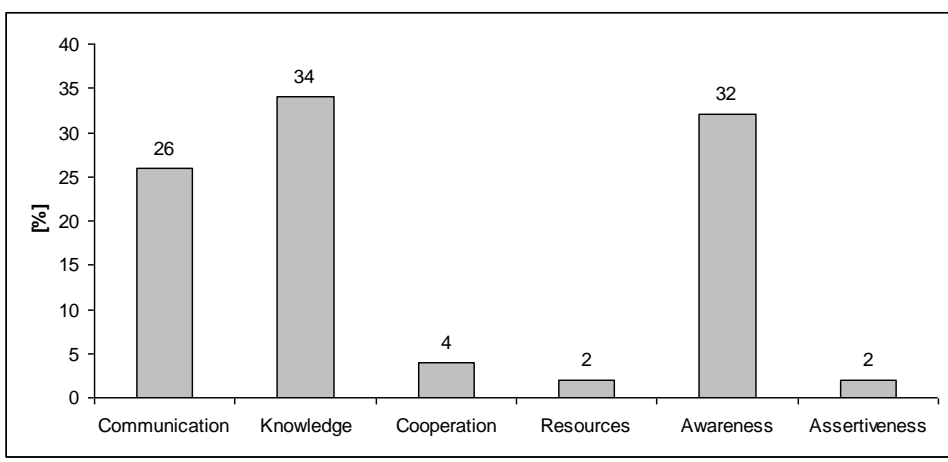

Fig. 5. Human factors, the lack of which adversely affects the effectiveness of fire-fighting and rescue operations

The next question was to identify these human factors, the excess of which adversely affects the effectiveness of rescue and firefighting activities. The highest percentage 
of respondents (30\%) pointed to fatigue, stress and pressure (25\% each). Responses of confidence and excess of norms were indicated by the $5 \%$ level, and the $10 \%$ dispersion. The results of the survey for this question are presented in Fig. 6.

In the next question, the respondents were to indicate those management actions which, in their opinion, aim to minimize the impact of the human factor on the general understood fire protection. The most frequently mentioned include: regular practical training (34\%), raising the attractiveness of training (33\%) and raising awareness (15\%). The least indications were obtained: technical and hardware protection (3\%), appropriate marking and messages (6\%) and cyclical theoretical training (9\%). The results of the survey for this survey question are presented in Table 3.

In the next question, the respondents were to indicate those management actions which, in their opinion, aim to minimize the impact of the human factor on the evacuation of the facilities. Respondents most often indicated regular practical trainings (56\%), raising the attractiveness of training (12\%) and appropriate marking and messages (10\%). In this part of the survey, cyclical theoretical training as well as technical and hardware protections obtained the least indications (2\% and $4 \%$ respectively). Answers of the respondents in this part confirm previous research results (Fig. 5) and indicate the legitimacy of conducting and repeating the practical exercises. According to the respondents and the knowledge base of experts in this area, appropriate markings as well as appropriate and precise messages in an emergency situation are also very important. Despite the proper planning and deployment of technical safeguards, the human factor can lead to the reduction of their effectiveness and to a large extent limit their impact on safe evacuation. The results of the survey for this survey question are presented in Table 4.

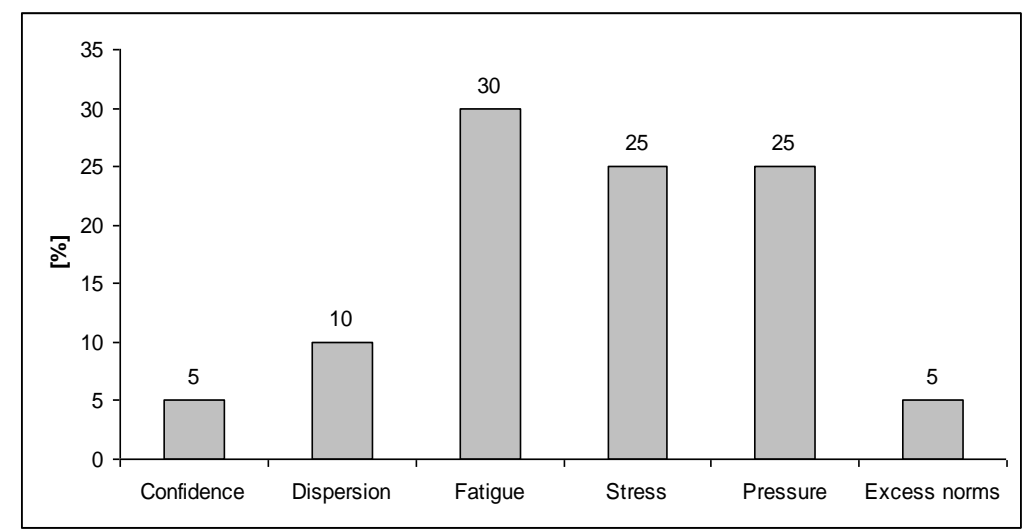

Fig. 6. Human factors, the excess of which adversely affects the effectiveness of fire-fighting and rescue operations

Table 3

Management actions aimed at minimizing the impact of the human factor on fire protection

\begin{tabular}{|l|c|}
\hline \multicolumn{1}{|c|}{ Type of activity } & Indication [\%] \\
\hline Cyclical theoretical training & 9 \\
\hline Regular practical training & 34 \\
\hline Raising the attractiveness of training & 33 \\
\hline Technical and hardware security & 3 \\
\hline Appropriate marking and messages & 6 \\
\hline Raising awareness & 15 \\
\hline
\end{tabular}


Table 4

Management actions aimed at minimizing the impact of the human factor on the evacuation of facilities

Source: Own research

\begin{tabular}{|l|c|}
\hline \multicolumn{1}{|c|}{ Type of activity } & Indication [\%] \\
\hline Cyclical theoretical training & 2 \\
\hline Regular practical training & 56 \\
\hline Raising the attractiveness of training & 12 \\
\hline Technical and hardware security & 4 \\
\hline Appropriate marking and messages & 10 \\
\hline Raising awareness & 16 \\
\hline
\end{tabular}

\section{CONCLUSIONS}

Despite the mandatory fire training, only $75 \%$ of respondents declare that such training took place. This probably results from the fact that students do not remember the fact that such training took place at the beginning of studies or at earlier stages of education. This thesis is confirmed by the next question about determining the level of knowledge acquired during the training, where $45 \%$ of respondents indicate that nothing from this training was memorable and $30 \%$ of the respondents remembered only half of the information provided. Participation in a trial or real evacuation from an object at risk is declared by $20 \%$ of respondents. Worrying is the declaration of $80 \%$ of respondents who have never had such experiences. The main reasons for such a situation may be: actual absence on a given day, negligence of facility administrators, failure to perform professional duties or non-adjustment to the level of users in given age ranges. It is highly probable that in a real threat situation such persons will behave in an inappropriate and unpredictable manner. It is purposeful in emergency situations to eliminate spontaneous behaviors and base on learned and practiced reflexes. This thesis is confirmed by the respondents indicating the very high usefulness of conducting emergency evacuation alarms (Fig. 4).

Another important conclusion is that qualifications in the field of fire protection are very important, which should result in the intensification of training of people staying in the facility and, above all, those responsible for fire safety and managers managing employee teams. Particular attention during evacuation training should be paid to knowledge and adherence to procedures that significantly limit the impact of the human factor by eliminating the lack of knowledge, awareness and communication errors (Fig. 5). Difficult factors such as fatigue, stress and pressure are difficult to eliminate and they are very important in critical situations requiring immediate decision-making. The elimination of the influence of these factors would be fundamental to the solid preparation of students at particular stages of education through the systematic exercise of procedures aimed at training subconscious reflexes.

This determines the scope of undertaken educational and management activities, which include: conducting cyclical and systematic practical training, raising awareness and raising the attractiveness of training to increase the assimilation of knowledge in the field of fire protection and evacuation rules from public buildings.

As research has shown, many people do not realize the low and ineffective level of training in the field of fire protection and evacuation rules from facilities, as well as the lack of practical exercises in this area. These deficiencies occur at every level of 
education. Therefore, it is very important that higher education institutions take up issues related to this subject in the study programs and teach responsibility and regularity in the education process. These processes should have a real dimension and leave abilities for permanent knowledge and proper reflexes acquired.

\section{REFERENCES}

Dul, J., Bruder, R., Buckle, P., Carayon, P., Falzon P., Marras, W.S., 2012. A strategy for human factors, Ergonomics: developing the discipline and profession, 377-395.

Holubová, V., 2016. Integrated safety management systems, Polish Journal of Management Studies, 14(1), 106-118, DOI: 10.17512/pjms.2016.14.1.10

Kopczewski, M., Pączek, B., Tobolski, M., 2012. Zarządzanie ochroną przeciwpożarową w małej i średniej firmie, Konferencja IZIP, Zakopane.

Laurowski, T., 2010. Vademecum ochrony przeciwpożarowej, Wyd. KaBe, Krosno.

Moraru, R., Sroka, M., 2018. Improved Education and Trainings in the Field of Fire Protection, „MATEC Web of Conferences” vol. 183.

Patankar, M.S., James, C. Taylor, J.C., 2017. Human Factors In Aviation Maintenance, Subjects Engineering \& Technology, ISBN9781351957687.

Tabor, J., 2015. Management of technical prevention systems in manufacturing companies, Polish Journal of Management Studies 12(1), 198-208. 